\title{
Cutting a mediolateral episiotomy at the correct angle: evaluation of a new device, the Episcissors-60
}

This article was published in the following Dove Press journal:

Medical Devices: Evidence and Research

2I February 20I4

Number of times this article has been viewed

\section{RM Freeman ${ }^{1,2}$ \\ HJ Hollands' \\ LF Barron ${ }^{3}$ \\ DS Kapoor ${ }^{4}$}

'Directorate of Obstetrics and Gynaecology, Plymouth Hospitals NHS Trust, Derriford Hospital, ${ }^{2}$ Plymouth University Peninsula Schools of Medicine and Dentistry, ${ }^{3}$ Directorate of Healthcare Science and Technology at Plymouth Hospitals NHS Trust, Derriford Hospital, Plymouth, ${ }^{4}$ Urogynaecology Unit, Royal Bournemouth Hospital, Bournemouth, UK
Correspondence: RM Freeman Directorate of Obstetrics and Gynaecology, Derriford Hospital, Plymouth PL6 8DH, UK Email robert.freeman@nhs.net
Background: Anal incontinence is nine times more prevalent in women than in men due to obstetric anal sphincter injury (OASI). OASI is linked to midline episiotomies and mediolateral episiotomies with post-delivery angles of $<30$ and $>60$ degrees. Studies show that doctors and midwives are unable to correctly "eyeball" the safe angle required due to perineal stretching by the fetal head at crowning. A new scissor instrument (Episcissors-60) was devised to allow cutting a mediolateral episiotomy at a fixed angle of 60 degrees from the perineal midline.

Methods: Scissors with a marker guide limb pointing towards the anus were devised, ensuring an angle of 60 degrees between the scissor blades and the guide limb. This device was initially tested in models. Post-delivery angles were recorded on transparencies and analyzed by an author blinded to clinical details. Accoucheurs were asked to rate the ease of use on a 5-point scale.

Results: Of the 17 women, 14 delivered with ventouse, two with forceps, and one with sequential ventouse-forceps. Indications for instrumental delivery were suboptimal cardiotocogram and/or prolonged second stage of labor. Mean birth weight was $3.41(2.92-4.12) \mathrm{kg}$. A mean postdelivery angle of $42.4 \pm 7$ (range 30-60, median 43) degrees (95\% confidence interval 38.8-46) was achieved with the Episcissors-60 instrument. Eighty-eight percent of clinicians agreed or strongly agreed that the scissors were easy to use.

Conclusion: The Episcissors-60 delivered a consistent post-delivery angle of 43 degrees. They could replace "eyeballing" when performing mediolateral episiotomies and form part of a preventative strategy to reduce OASI.

Keywords: 60 degree episiotomy, anal incontinence, episiotomy scissors, mediolateral episiotomy, obstetric anal sphincter injury, OASI

\section{Introduction}

Anal incontinence (ie, incontinence of liquid feces and flatus) can have a devastating impact on a person's quality of life. It is well known that obstetric anal sphincter injury (OASI) is a major risk factor for anal incontinence in women, leading to a nine-fold increase in anal incontinence compared with men. A 10-year, prospective, follow-up study of women with OASI revealed an incidence of $36 \%,{ }^{1}$ and a meta-analysis of 717 patients found that $30 \%$ of women were symptomatic one year after OASI. ${ }^{2}$ The probability of longer-term anal incontinence and urgency is thought to be as high as $53 \%-80 \%,{ }^{3,4}$ with obvious effects on quality of life.

It is therefore important that preventative measures are implemented at the time of vaginal delivery, not only because of the risk of such long-term complications following OASI but also in view of the immediate cost. For example, based on a $5.9 \%$ incidence of OASI in primiparous women (325,000 per annum) from Hospital Episode Statistics 
data, ${ }^{5}$ it is estimated that there would be 20,000 new cases of OASI alone in this group. The incidence in higher order births is $1.5 \%$ for normal births and $3.4 \%$ for instrumental births, averaging about $2 \%$ overall. The number of new OASI cases is nearly 10,000 in this group. Based on these robust estimates, the overall incidence of OASI in the UK is 30,000 new cases each year. The direct medical costs of OASI repair, investigations including hospital appointments, and endoanal physiology (ie, manometry and ultrasound) would be $£ 48.75$ million per annum.

The Royal College of Obstetricians and Gynaecologists' guidelines ${ }^{6}$ recommend that all women who have sustained OASI should have appropriate investigation by endoanal ultrasound, and that those who have sphincter defects and/or poor anal manometric pressures, and are symptomatic; should have the option of elective cesarean birth. The above cost estimates might increase further because many affected women will require cesarean section in a subsequent pregnancy.

The incidence of OASI appears to be increasing, with data from Scotland and Scandinavia showing a 2-3-fold increase over a 10-year period (particularly for women in a first pregnancy), ${ }^{7,8}$ while a recent report from Hospital Episode Statistics in England has revealed a larger increase from $1.8 \%$ to $5.9 \%$ between 2000 and $2012 .{ }^{5}$ While this study attributes the increased incidence of OASI in part to improved detection, other factors have been also been implicated, ie, wider application of the "hands-poised" approach, combined with the "reluctance to use episiotomies"..$^{7-11}$

The evidence that episiotomy prevents OASI and/or anal incontinence is conflicting, with some studies showing a protective effect ${ }^{12,13}$ and others not. ${ }^{14,15}$ A possible reason for the difference might relate to the angle at which the episiotomy is cut. For example, in some parts of the USA, episiotomies continue to be performed in the midline, and these have been shown to have a $20 \%$ risk of extension into the anal sphincter. ${ }^{16}$ In Europe by comparison, the episiotomy incision is recommended at a 45-60 degree angle. However, this can be difficult to achieve at crowning when the perineum is fully stretched. Kalis et $\mathrm{a} \mathrm{l}^{17}$ have shown that an episiotomy performed at 40 degrees results in a post-delivery angle of 22 degrees, which is too close to the midline (Figure 1). It is only a 60 degree episiotomy that results in a post-delivery angle of 45 degrees (Figure 2).$^{18}$ There is therefore a need for an instrument that will accurately cut a 60 degree angled episiotomy at crowning.

The concept and initial design of a device to do this (the Episcissors-60) arose in the Urogynaecology Unit and the Directorate of Healthcare Science and Technology at Plymouth Hospitals NHS Trust. The purpose of this evaluation was to establish whether an episiotomy performed at an angle of 60 degrees using a prototype of the Episcissors- 60 at crowning produced an angle of 45 degrees as measured after delivery.

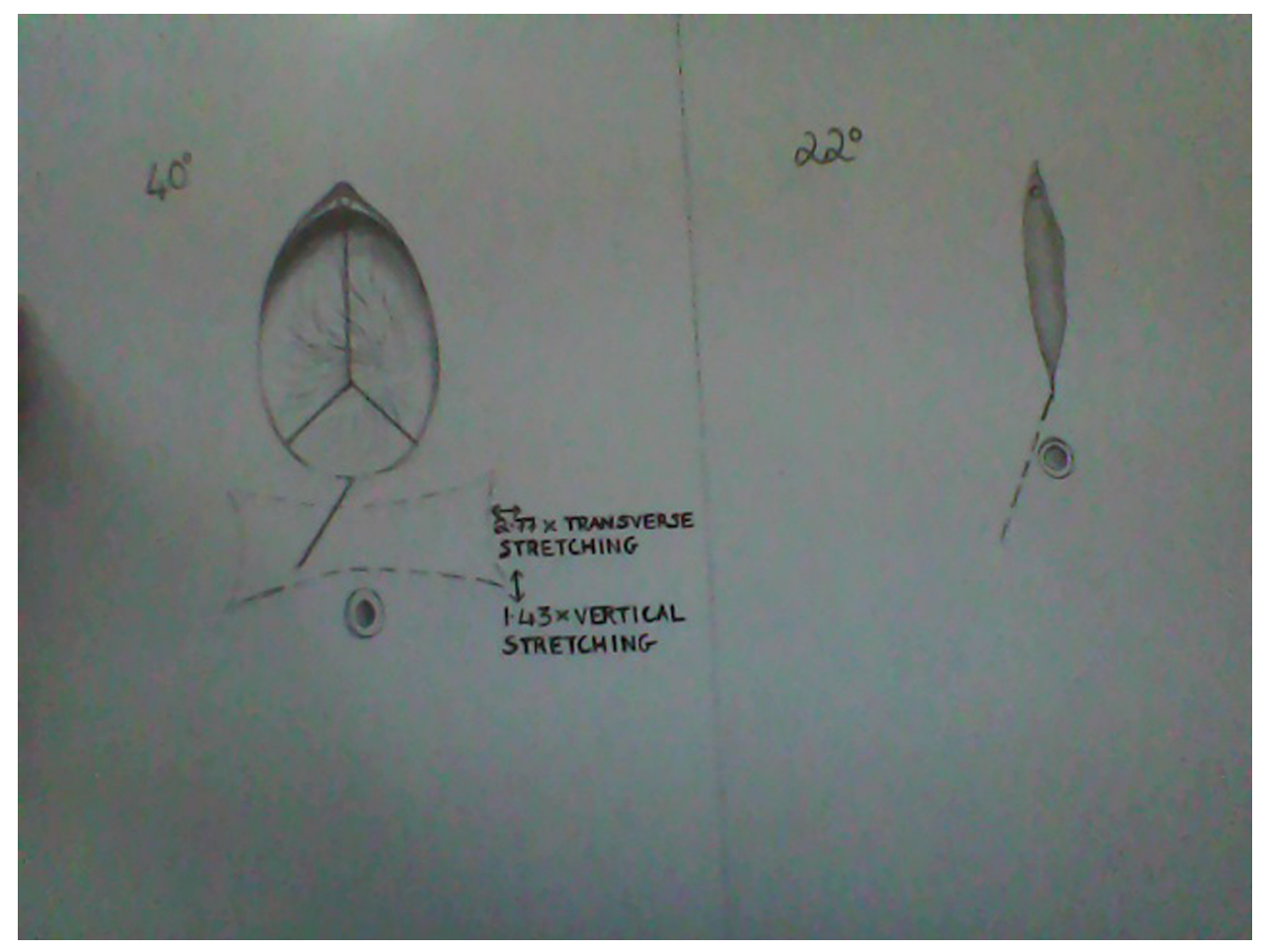

Figure I 40 degree episiotomy at crowning resulting in a 22 degree post-delivery angle. 

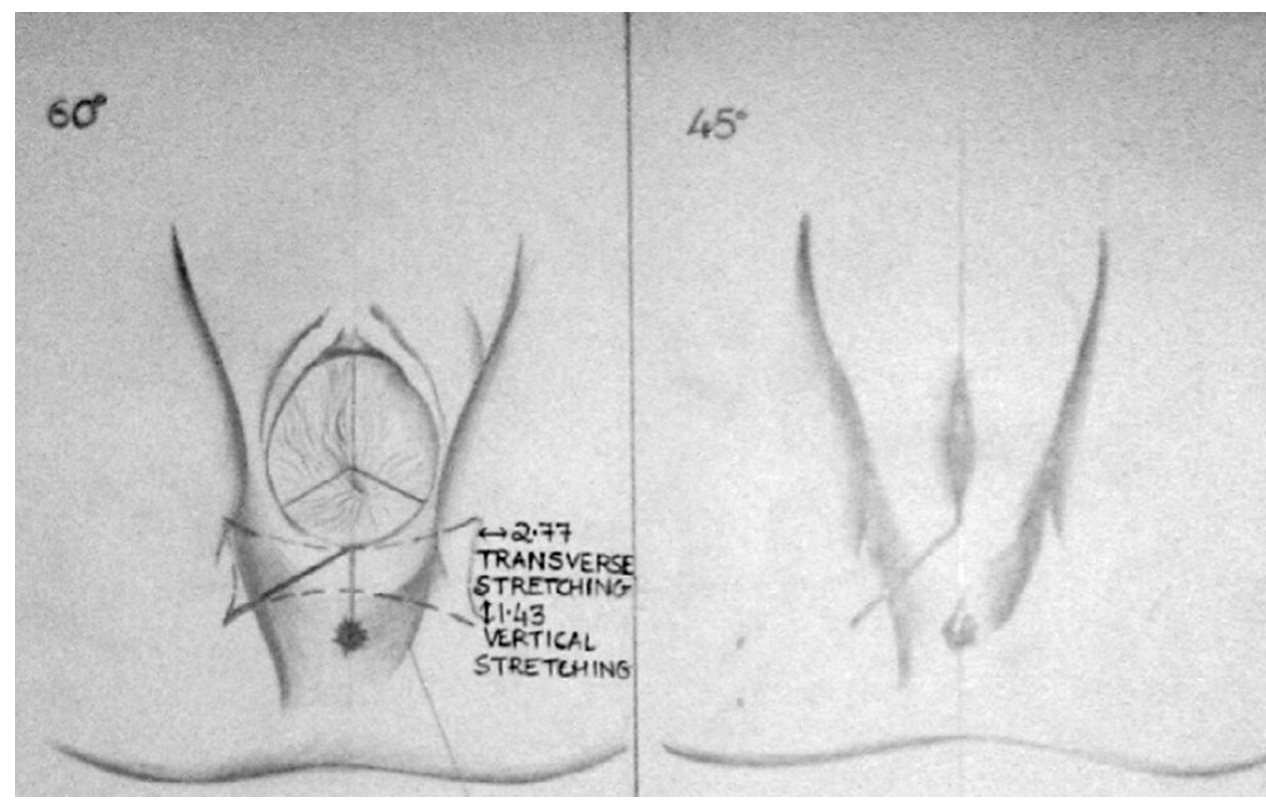

Figure 260 degree episiotomy at crowning resulting in a 45 degree post-delivery angle.

\section{Materials and methods}

The concept was a simple one, ie, a guide limb was placed at the fulcrum of a pair of Mayo scissors used for episiotomy. The angle between the blades and the rod was 60 degrees.

For clinical use, the guide limb is placed at the midpoint of the introitus and aligned to the anus (Figure 3). The cut is then performed while keeping the guide limb in the correct position. This prototype was initially tested on models and

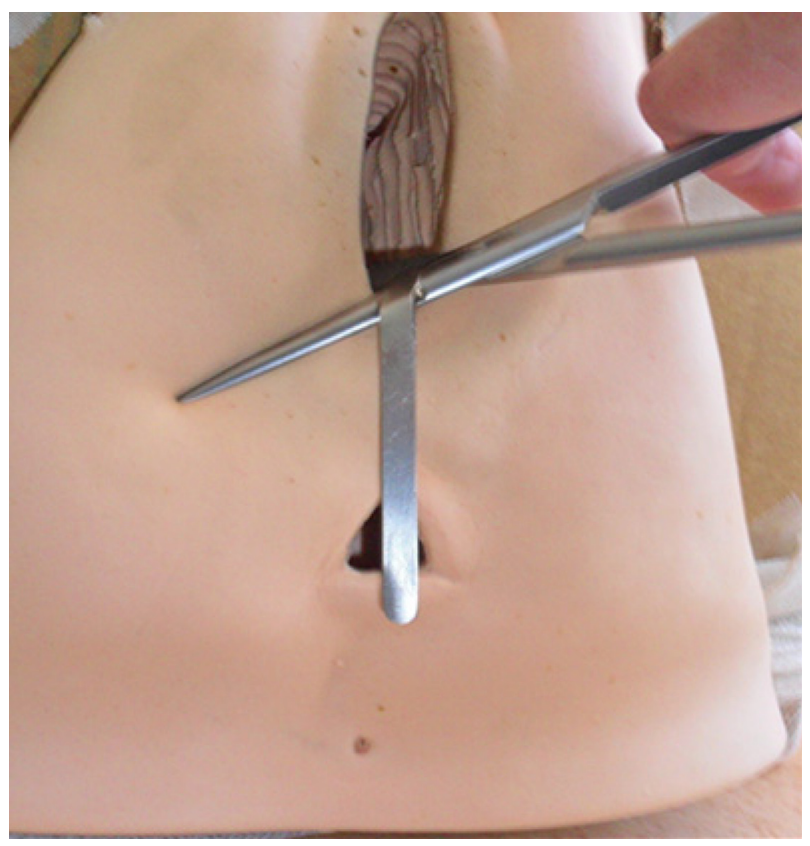

Figure 3 Original Episcissors-60. then as an evaluation in 17 patients undergoing instrumental vaginal delivery.

The evaluation ran from October 2011 until February 2012. It was decided that evaluation of the instrument should take place in women most likely to need an episiotomy, ie, those having instrumental delivery (ventouse or forceps), as recommended by the National Institute for Health and Care Excellence guideline on intrapartum care.

Training on the use of a prototype of the Episcissors- 60 (Figure 3) and recording the sutured angle was given to experienced obstetric trainees in the delivery suite. They were also asked to complete a short pro forma following usage to assess ease of use of the instrument plus any other comments. This was on a 5-point scale, ie, "strongly agree", "tend to agree", "neither agree or disagree", "tend to disagree", and "strongly disagree".

After suturing, the angle in relation to the anus was drawn onto a piece of sterile transparency placed over the perineum by the obstetric trainee. This was then placed in a sterile bag and given to one of the investigators $(\mathrm{HJH})$ blinded to all patient details. She subsequently measured the angle using a protractor.

No patient follow-up was involved because this was a proof of concept/medical device evaluation. Approval for the evaluation was given by the research and development committee of Plymouth Hospitals NHS Trust.

\section{Results}

For this evaluation, a total of 17 episiotomies were performed at instrumental deliveries by trainees/registrars. 
Of the 17 instrumental deliveries, 14 were ventouse, two were low forceps, and one was sequential ventouse-forceps. The indications for instrumental delivery were suboptimal cardiotocogram and/or prolonged second stage of labor. Mean birth weight was $3.41(2.92-4.12) \mathrm{kg}$. The mean post-delivery angle was $42.4 \pm 7$ (30-60) degrees. The median value was 43 degrees (95\% confidence interval 38.8-46), suggesting a normal distribution. One patient suffered a grade $3 \mathrm{a}$ OASI (episiotomy scar angle of 30 degrees).

The trainees rated the ease of use of the instrument on a 5-point scale ("strongly agree", "tend to agree", "neither agree or disagree", "tend to disagree", and "strongly disagree"). In ten cases, this was "strongly agree", in five it was "tend to agree", in one it was "neither agree or disagree", and in one it was "strongly disagree". The comments for "tend to agree" were in relation to the length of the cut. For example, the incision could not be extended because the blades of the scissors were not felt to be of sufficient length. In the "strongly disagree" case, the accoucheur was lefthanded and unable to orientate herself into a position to align the Episcissors-60. Since this study, the prototype scissors have undergone design changes that provide a flexible guide to accommodate the baby's head. The length of the scissor blades is now an unencumbered $5 \mathrm{~cm}$ (Figure 4).

\section{Discussion}

The results of this study have shown that, following use of an Episcissors-60 device, the mean post-delivery episiotomy angle produced is 43 degrees. While this is not the 45 degrees originally expected, it is still greater than that seen with visual measurement only, ie, so-called "eyeballing". For example, in one study reviewing the episiotomy scar angle after delivery, no midwife and only $20 \%$ of doctors performed an

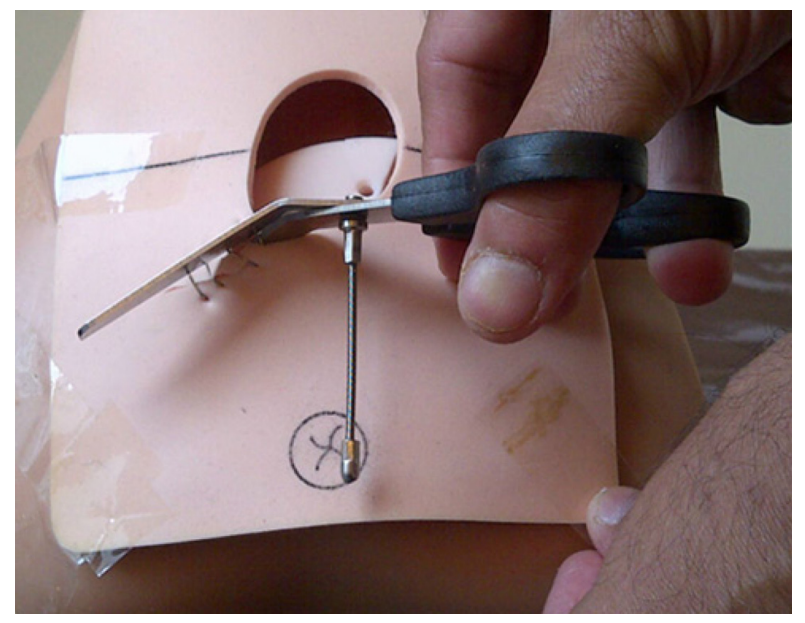

Figure 4 Episcissors-60 (new version) photo. episiotomy at the "correct" angle. ${ }^{19}$ In patients with OASI, despite an episiotomy, the suture angle after delivery was only 30 degrees versus 38 degrees in those without OASI, ie, in neither group was 45-60 degrees achieved. However, the authors reported a $50 \%$ reduction in risk for every 6 degrees cut away from midline. ${ }^{20}$ Similar results were noted by Andrews et al, who described angles of 26 degrees in cases and 37 degrees in controls. ${ }^{19}$ Stedenfeldt et $\mathrm{al}^{21}$ found a safety zone of 30-60 degrees for the post-delivery angle, with a significantly increased incidence of OASI in a U-shaped fashion with angles outside this zone. They also found that episiotomies originating $9 \mathrm{~mm}$ away from the posterior fourchette after birth were associated with a reduction in OASI.

In the present evaluation, one patient suffered a $3 \mathrm{a}$ OASI/tear following a failed ventouse delivery which was converted to a forceps delivery. The suture angle in this patient was 30 degrees. The indication for instrumental delivery was a suboptimal cardiotocogram. The experiments by Kalis et $\mathrm{al}^{17,18}$ suggested that an angle of 40 degrees is probably too acute to prevent potential sphincter damage and showed that an incision angle at crowning of 60 degrees will result in a 45-degree angle after delivery.

In the most recent study from England reviewing national statistics, the factor associated with the lowest rate of OASI was episiotomy. ${ }^{5}$ This and the results from other studies would suggest that, especially in higher-risk women, episiotomy should be considered as a form of OASI prevention. Such risk groups include primigravid women, those with a short perineal body, instrumental delivery, occiput posterior position, post-maturity, and previous OASI. ${ }^{21}$ For vacuum delivery, the data suggest a protective effect of episiotomy in prevention of OASI. ${ }^{12,13}$

However, episiotomies are not commonly performed at normal deliveries by midwives, presumably because the evidence base is inconclusive and due to the perceived high incidence of pain, infection, and wound breakdown, along with delay in resumption of intercourse following episiotomy. ${ }^{22,23}$ For example, a survey of randomly selected labor ward midwives in 50 obstetric units in England ${ }^{24}$ revealed that $37 \%$ of midwives would never perform an episiotomy and only 19.4\% would undertake one if there was the impression that the perineum was about to tear. As a result, it is likely that many have not received training in episiotomy performance in recent years.

Prevention of OASI should be the aim of all health care professionals involved in childbirth, and the multicenter interventional program in Norway ${ }^{25}$ is without doubt a glowing demonstration of how this can be achieved. The evidence that a correctly performed episiotomy can be preventative is growing, 
and training in the technique, in particular performing the cut at an angle of 60 degrees, should help achieve this aim.

The prototype Episcissors- 60 has demonstrated that a median angle of 43 degrees can be achieved. This is marginally less than the 45 degrees expected. However, the postdelivery angles obtained in this study are more consistent and superior to those described in the literature with the current practice of eyeballing. ${ }^{19}$ No midwife and $22 \%$ of doctors achieved an episiotomy within the safety zone in that study. Moreover, the perineum is spherical at the time of crowning, and this leads to further difficulty in the ability to guess the angle. It is also interesting to consider work by Tincello et al, ${ }^{26}$ which showed that doctors and midwives are unable to correctly guess the angle, even on paper. It could be argued that better training might improve the visual accuracy of eyeballing. To the best of our knowledge, there are no validated training courses to improve eyeballing.

It is also worth questioning the obstetric practice of eyeballing in relation to other specialties in modern medicine. Orthopedic surgeons, breast surgeons, sonographers, and pathologists all use relevant measuring instruments to enable their practice rather than relying on eyeballing.

\section{Conclusion}

The Episcissors-60 delivered a consistent post-delivery episiotomy angle of 43 degrees. This device could replace eyeballing when performing mediolateral episiotomies and may form part of a preventative strategy to reduce OASI.

\section{Author contributions}

All the named authors contributed to writing this paper. RMF and HJH contributed to the protocol/project development, data collection or management, data analysis, and manuscript writing/editing. LFB and DSK contributed to the protocol/ project development, and manuscript writing/editing. All authors agree to be accountable for all aspects of the work.

\section{Disclosure}

All four authors designed and are coinventors of the Episcissors-60 instrument. As a result, once the scissors are commercialized, they are eligible for a share of royalties under Department of Health policy. Plymouth Hospitals NHS Trust owns the intellectual property rights and will also be eligible for payment. DSK owns shares in the company responsible for commercialization of the scissors. RMF is a locality lead for the Peninsula CLAHRC and this paper presents independent research commissioned by the National Institute for Health Research. The views expressed in this publication are those of the author and not necessarily those of the National Health Service, the National Institute for Health Research, or the Department of Health.

\section{References}

1. Fornell E, Matthiesen L, Sjodahl R, Berg G. Obstetric anal sphincter injury ten years after: subjective and objective long term effects. BJOG. 2005;112:312-316.

2. Pollack J, Nordenstam J, Brismar S, Lopez A, Altman D, Zetterstrom J. Anal incontinence after vaginal delivery: a five-year prospective cohort study. Obstet Gynecol. 2004;104:1397-1402.

3. Evers EC, Blomquist JL, McDermott KC, Handa VL. Obstetrical anal sphincter laceration and anal incontinence 5-10 years after childbirth. Am J Obstet Gynecol. 2012;207:425. e1-e6.

4. Soerensen MM, Buntzen S, Bek KM, Laurberg S. Complete obstetric anal sphincter tear and risk of long-term fecal incontinence: a cohort study. Dis Colon Rectum. 2013;56:992-1001.

5. Gurol-Urganci I, Cromwell D, Edozien L, et al. Third- and fourth-degree perineal tears among primiparous women in England between 2000 and 2012: time trends and risk factors. BJOG. 2013;120(12):1516-1525.

6. Royal College of Obstetricians and Gynaecologists. The management of third and fourth degree perineal tears. Green top guideline No 29. London, UK: Royal College of Obstetricians and Gynaecologists; 2007.

7. Tyagi V, Perera M, Guerrero K. Trends in obstetric anal sphincter injuries over 10 years - incidence and risk factors. Presented at the 2011 meeting of the International Continence Society, August 29-September 2, 2011, Glasgow, Scotland.

8. Laine K, Gissler M, Pirhonen J. Changing incidence of anal sphincter tears in four Nordic countries through the last decades. Eur J Obstet Gynecol Reprod Biol. 2009;146:71-75.

9. Jonsson E, Elfaghi I, Rydhstrom H, Herbst A. Modified Ritgen's maneuver for anal sphincter injury at delivery: a randomized controlled trial. Obstet Gynecol. 2008;112:212-217.

10. Revicky V, Nirmal D, Mukhopadhyay S, Morris EP, Nieto JJ. Could a mediolateral episiotomy prevent obstetric anal sphincter injury? Eur J Obstet Gynecol Reprod Biol. 2010;150:142-146.

11. Pirhonen JP, Grenman SE, Haadem K, et al. Frequency of anal sphincter rupture at delivery in Sweden and Finland - result of difference in manual help to the baby's head. Acta Obstet Gynecol Scand. 1998;77: 974-977.

12. de Leeuw JW, Struijk PC, Vierhout ME, Wallenburg HCS. Risk factors for third degree perineal ruptures during delivery. BJOG. 2001;108:383-387.

13. Räisänen S, Vehviläinen-Julkunen K, Heinonen S. Need for and consequences of episiotomy in vaginal birth: a critical approach. Midwifery. 2010;26:348-356.

14. Andrews V, Sultan AH, Thakar R, Jones PW. Occult anal sphincter injuries - myth or reality? BJOG. 2006;113:195-200.

15. Fritel X, Schaal JP, Fauconnier A, Bertrand V, Levet C, Pigne A. Pelvic floor disorders 4 years after first delivery: a comparative study of restrictive versus systematic episiotomy. BJOG. 2008;115:247-252.

16. Lappen JR, Gossett DR. Changes in episiotomy practice: evidence-based medicine in action. Expert Rev Obstet Gynecol. 2010;5:301-309.

17. Kalis V, Karbanova J, Horak M, Lobovsky L, Kralickova M, Rokyta Z. The incision angle of mediolateral episiotomy before delivery and after repair. Int J Gynecol Obstet. 2008;103:5-8.

18. Kalis V, Landsmanova J, Bednarova B, Karbanova J, Laine K, Rokyta Z. Evaluation of the incision angle of mediolateral episiotomy at 60 degrees. Int J Gynecol Obstet. 2011;112:220-224.

19. Andrews V, Thakar R, Sultan AH, Jones PW. Are mediolateral episiotomies actually mediolateral? BJOG. 2005;112:1156-1158.

20. Eogan M, Daly L, O'Connell PR, O'Herlihy C. Does the angle of episiotomy affect the incidence of anal sphincter injury? BJOG. 2006;113:190-194. 
21. Stedenfeldt M, Pirhonen J, Blix E, Wilsqaard T, Vonen B, Qian P. Episiotomy characteristics and risks for obstetric anal sphincter injury: a case-control study. BJOG. 2012;119:724-730.

22. Power D, Fitzpatrick M, O’Herlihy C. Obstetric anal sphincter injury: how to avoid, how to repair: a literature review. J Fam Pract. 2006;55: 193-200.

23. Albers LL, Borders N. Minimizing genital tract trauma and related pain following spontaneous vaginal birth. J Midwifery Womens Health. 2007;52:246-253.
24. Trochez R, Waterfield M, Freeman R. Hands on or hands off the perineum: a survey of care of the perineum in labour (HOOPS). Int Urogynecol J. 2011;22:1279-1285.

25. Hals E, Oian P, Pirhonen T, et al. A multicenter interventional program to reduce the incidence of anal sphincter tears. Obstet Gynecol. 2010;116:901-908.

26. Tincello DG, Williams A, Fowler GE, Adams EJ, Richmond DH, Alfirevic Z. Differences in episiotomy technique between midwives and doctors. BJOG. 2003;110:1041-1044.

\section{Publish your work in this journal}

Medical Devices: Evidence and Research is an international, peerreviewed, open access journal that focuses on the evidence, technology, research, and expert opinion supporting the use and application of medical devices in the diagnosis, treatment and management of clinical conditions and physiological processes. The identification of novel devices and optimal use of existing devices which will lead to improved clinical outcomes and more effective patient management and safety is a key feature. The manuscript management system is completely online and includes a quick and fair peer-review system. Visit http://www. dovepress.com/testimonials.php to read real quotes from authors.

Submit your manuscript here: http://www.dovepress.com/medical-devices-evidence-and-research-journal 